\title{
Video Article \\ Method to Produce Durable Pellets at Lower Energy Consumption Using High Moisture Corn Stover and a Corn Starch Binder in a Flat Die Pellet Mill
}

\author{
Jaya Shankar Tumuluru ${ }^{1}$, Craig C. Conner ${ }^{1}$, Amber N. Hoover ${ }^{1}$ \\ ${ }^{1}$ Biofuels and Renewable Energy Technology Department, Idaho National Laboratory \\ Correspondence to: Jaya Shankar Tumuluru at jayashankar.tumuluru@inl.gov
}

URL: https://www.jove.com/video/54092

DOI: doi:10.3791/54092

Keywords: Environmental Sciences, Issue 112, Corn stover, high moisture pelleting, process variables, starch binder, pellet properties, specific energy consumption

Date Published: 6/15/2016

Citation: Tumuluru, J.S., Conner, C.C., Hoover, A.N. Method to Produce Durable Pellets at Lower Energy Consumption Using High Moisture Corn Stover and a Corn Starch Binder in a Flat Die Pellet Mill. J. Vis. Exp. (112), e54092, doi:10.3791/54092 (2016).

\section{Abstract}

A major challenge in the production of pellets is the high cost associated with drying biomass from 30 to $10 \%$ (w.b.) moisture content. At Idaho National Laboratory, a high-moisture pelleting process was developed to reduce the drying cost. In this process the biomass pellets are produced at higher feedstock moisture contents than conventional methods, and the high moisture pellets produced are further dried in energy efficient dryers. This process helps to reduce the feedstock moisture content by about $5-10 \%$ during pelleting, which is mainly due to frictional heat developed in the die. The objective of this research was to explore how binder addition influences the pellet quality and energy consumption of the high-moisture pelleting process in a flat die pellet mill. In the present study, raw corn stover was pelleted at moistures of 33,36 , and $39 \%$ (w.b.) by addition of 0,2 , and $4 \%$ pure corn starch. The partially dried pellets produced were further dried in a laboratory oven at $70{ }^{\circ} \mathrm{C}$ for $3-4$ $\mathrm{hr}$ to lower the pellet moisture to less than $9 \%$ (w.b.). The high moisture and dried pellets were evaluated for their physical properties, such as bulk density and durability. The results indicated that increasing the binder percentage to $4 \%$ improved pellet durability and reduced the specific energy consumption by $20-40 \%$ compared to pellets with no binder. At higher binder addition (4\%), the reduction in feedstock moisture during pelleting was $<4 \%$, whereas the reduction was about $7-8 \%$ without the binder. With $4 \%$ binder and $33 \%$ (w.b.) feedstock moisture content, the bulk density and durability values observed of the dried pellets were $>510 \mathrm{~kg} / \mathrm{m}^{3}$ and $>98 \%$, respectively, and the percent fine particles generated was reduced to $<3 \%$.

\section{Video Link}

The video component of this article can be found at https://www.jove.com/video/54092/

\section{Introduction}

Biomass is one of the major energy resources in the world and is considered carbon neutral ${ }^{1}$. Bulk density of baled and ground agricultural biomass and chipped woody biomass is low. Low bulk densities of baled biomass $\left(130-160 \mathrm{~kg} / \mathrm{m}^{3}\right)$, ground biomass $\left(60-80 \mathrm{~kg} / \mathrm{m}^{3}\right)$ and chipped woody biomass $\left(200-250 \mathrm{~kg} / \mathrm{m}^{3}\right)$ create storage, transportation, and handling issues ${ }^{2,3}$. Densifying or compressing the ground biomass by using pressure and temperature increases the bulk density by about 5 to 7 times, and helps to overcome transportation and storage limitations ${ }^{4}$. Pellet mills, briquette presses, and screw extruders are densification systems typically used for biomass ${ }^{4}$. Breakeven transportation distance analysis on baled and pelleted biomass feedstock indicated that pellets can be transported 1.6 times farther than bales using a truck for the same cost ${ }^{5}$. The transportation efficiencies of pellets increase with other modes of transportation such as rail, since it is volume-limited compared to trucks that are limited by weight. Currently, in Europe the pellets produced from woody biomass are extensively used for bio-power generation. Canada and the United States are the major producers and suppliers of wood pellets to Europe ${ }^{6}$. Pellets produced from both woody and herbaceous biomass can be used for both thermochemical (cofiring, gasification, and pyrolysis) and biochemical conversion (ethanol) applications ${ }^{7-9}$.

The qualities of pellets (density and durability) and specific energy consumption of the pelleting process are dependent on the pellet mill process variables, such as die diameter, die speed and length to diameter ratio of the die and feedstock variables, such as feedstock moisture content and composition ${ }^{4}$. Both pellet mill process variables and feedstock variables influence the quality of the pellets and the specific energy used in the process. The die dimensions (i.e., length to diameter ratio) will influence the compression and extrusion pressure, and the die rotational speed controls the residence time of the material within the die. Moisture content is a feedstock variable that plays an important role by interacting with the biomass composition components (i.e., protein, starch, and lignin) due to high temperature and pressure encountered in the die. The presence of moisture increases the van der Waals forces, thereby increasing the attraction between the biomass particles ${ }^{10}$. In general, higher moisture in the biomass impacts the bulk density of the compressed product due to diametrical and lateral expansion as it exits the pellet mill or briquette press die ${ }^{10}$. Biomass composition, such as starch, protein, lignin, and other water-soluble carbohydrates, influences the binding behavior when subjected to pressure and temperature in densification equipment ${ }^{11}$. Some of the common composition reactions that are influenced by feedstock moisture, die temperature, and pressure are starch gelatinization, protein denaturation, and lignin glass transition. Generally, at temperatures of $100{ }^{\circ} \mathrm{C}$ or greater and a feedstock moisture content of greater than $30 \%$, starch in food and animal feed gets gelatinized and influences textural properties like hardness ${ }^{12}$. Typically, the starch reactions are gelatinization, pasting, and retrogradation. Among these reactions, gelatinization has the greatest influence on pellet properties ${ }^{13}$. Starch is often included in food and non-food applications 
as a binder. For example, in the pharmaceutical tablet formulation starch is used as filler ${ }^{4,14}$. Protein in the biomass undergoes denaturation and forms complex bonds due to the high temperature and pressure experienced in the densification process ${ }^{11}$. In general, higher amounts of protein in biomass will result in a more durable pellet ${ }^{15,16}$. For example, alfalfa, which has a higher amount of protein, results in durable pellets at higher feedstock moisture content. The fat in the biomass reduces the friction forces and the extrusion energy during pelleting or briquetting ${ }^{11,17}$. In lignocellulosic biomass, the presence of lignin within plant material helps to form pellets without adding any binders ${ }^{18}$. Woody biomass has higher lignin content (29-33\%) when compared to a herbaceous biomass, which typically consists of $12-16 \%$ lignin ${ }^{4,19}$. At lower feedstock moisture contents of about $10-12 \%$ (w.b.), glass transition temperature of the lignin is greater than $140{ }^{\circ} \mathrm{C}^{20}$; whereas, increasing the moisture content reduces the glass transition temperature ${ }^{21}$. According to Lehtikangas ${ }^{22}$, the glass transition temperature of lignin at $8-15 \%$ (w.b.) moisture content is about $100-135^{\circ} \mathrm{C}$, but increasing the moisture content to $>25 \%$ (w.b.) reduces the glass transition temperature to $<90{ }^{\circ} \mathrm{C}$.

Herbaceous biomass is available at higher moisture content depending on the harvesting method and harvesting time. In the case of single pass harvesting method the harvested material will have a moisture content $>30 \%$ (w.b.) ${ }^{23}$. Biomass is typically dried to about $10 \%$ (w.b.) moisture content to make it aerobically stable and to prevent dry matter loss during storage. Lamers et al. ${ }^{24}$ indicated that to preprocess biomass at $30 \%$ moisture content the total cost for both grinding (stages $1 \& 2$ ) and drying is about $\$ 43.60 /$ dry ton, and about $\$ 15.00 /$ dry ton is just for drying the biomass. Drying biomass takes about $65 \%$ of the total preprocessing energy, and pelleting takes about $8-9 \%{ }^{24}$. Yancey et al. ${ }^{25}$ has corroborated the fact that drying is the major energy consumer in biomass preprocessing. The experimental data and techno-economic analysis indicated that efficient moisture management is critical for reducing the biomass preprocessing costs. One way to decrease the drying cost and manage the feedstock moisture more efficiently is to use a high-moisture pelleting process coupled with a low temperature drying method. In the highmoisture pelleting process developed at Idaho National Laboratory, the biomass is pelleted at moisture contents greater than $28 \%$ (w.b.); the partially dried pellets produced, which are still high in moisture, can be dried in energy efficient driers, such as grain or belt dryers ${ }^{21}$. One major advantage of high-moisture pelleting is that it helps reduce the drying cost, which in turn results in reduced total pellet production cost. Technoeconomic analysis indicated that energy and production costs are reduced by about $40-50 \%$ using the high-moisture pelleting process compared to a conventional pelleting method ${ }^{24,26}$. The major reason for reduced pellet production cost is due to replacing a rotary dryer that operates at high temperatures of 160 to $180^{\circ} \mathrm{C}$ with a grain dryer that operates at lower temperatures of about $80{ }^{\circ} \mathrm{C}$ or less ${ }^{21}$. The other advantages of replacing a rotary dryer with a belt or grain dryer are: 1) greater efficiency, 2) reduced fire hazard, 3) does not need high quality heat, 4) reduced volatile organic compound (VOC) emissions, 5 ) reduced particulate emissions, and 6) does not agglomerate high clay or sticky biomass ${ }^{27}$. The energy-intensive steam conditioning step in conventional pelleting, typically used to add moisture and activate some of the biomass components, is replaced with a short preheating step. This step helps reduce the feedstock moisture content as well as activate biomass components like lignin. The frictional heat developed in the pellet die also helps reduce the feedstock moisture content by about 5-8\% (w.b.) $)^{21,28}$. In the highmoisture pelleting process, the pellet mill not only compresses the biomass, but also helps to reduce the moisture content during compression and extrusion. Many researchers have done experiments on pelleting of raw and chemically pretreated biomass at a wide range of moisture contents $\left(7-45 \%\right.$, w.b.) using single, laboratory, pilot scale ring die and commercial continuous pelleting systems ${ }^{10,25,29-40,(P a c e, ~ D . ~ 2015 . ~ P e l l e t i n g ~ o f ~}$ municipal solid waste and ammonia fiber explosion (AFEX) pretreated corn stover in a pilot scale ring die pellet mill. Biofuels Department, Chief Engineer, Biomass National User Facility, Idaho National Laboratory (Unpublished data))

. These researchers adjusted feedstock moisture content of the biomass to different desired levels to understand the effect of moisture content on quality attributes of the pellets.

Pellet quality attributes, bulk density and durability, are normative specifications according to the USA based Pellet Fuel Institute (PFI). However, according to the European Committee for Standardization (CEN) durability is a normative and bulk density is an informative specification ${ }^{41}$. Pellets with durability values $>96.5 \%$ and bulk density $>640 \mathrm{~kg} / \mathrm{m}^{3}$ are designated as super premium pellets based on PFI standards, whereas pellets with durability values $>97.5 \%$ are designated as pellets with the highest grade. Both the CEN and PFI standards recommend pellets with different diameters. For example, PFI recommends a diameter in the range of $6.35-7.25 \mathrm{~mm}$, whereas CEN recommends a diameter ranging from $6-25 \mathrm{~mm}$ and a pellet length less than or equal to 4 times the diameter ${ }^{41}$. Smaller diameter pellets $(6 \mathrm{~mm})$ are preferred for transporting longer distances considering they have higher packing densities ${ }^{28}$. For conventional pelleting processes, it is recommended to pellet biomass at low moisture contents to meet these density specifications desirable for transporting the pellets long distances ${ }^{41}$. Both CEN and PFI have additional pellet grades ${ }^{41}$. Tumuluru ${ }^{28}$ and Tumuluru and Conner ${ }^{40}$ indicated that high moisture pelleting processes developed at Idaho National Laboratory help to produce corn stover and wood pellets with different quality attributes (bulk density and durability) and specific energy consumption making them suitable for different transportation and logistics scenarios.

Most of the pelleting studies on biomass were done using a single pelleting system. Pelleting data on biomass using a continuous system at laboratory scale is limited. Studies on continuous pelleting systems will be useful to understand the effect of the pelleting process variables like die rotational speed, length to diameter ratio and die diameter on the quality attributes and specific energy consumption. The pelleting data on the continuous systems can be further used to scale up the process to pilot and commercial scale systems. In general, a flat die pellet mill is used for conducting pelleting studies on woody and herbaceous biomass in a laboratory ${ }^{4}$. The working principle of the laboratory scale flat die, pilot, and commercial scale ring die pellet mills are similar. All of these pellet mills have a perforated hard steel die with two or three rollers. By rotating the die, the rollers exert force on the feedstock and force it through the perforations of the die to form densified pellets ${ }^{4}$.

Our earlier studies on high-moisture pelleting of corn stover at feedstock moisture content of 28-38\% (w.b.) without any binder addition resulted in lower durability values at higher feedstock moisture content ${ }^{21,28}$. Improving the durability of high moisture pellets after cooling and drying is important as it helps to prevent the disintegration of the pellets (loss of pellet quality) during handling, storage and transportation. The disintegration of pellets typically results in fines generation and loss of revenue for the pellet producers. Binders are typically used in the pelleting process to improve pellet quality, especially durability, and to reduce the specific energy consumption. Commonly used natural binders in the pelleting process are proteins and starch ${ }^{4,28}$. Starch undergoes gelatinization, whereas protein undergoes denaturation in the presence of heat, moisture, and pressure. Both of these reactions result in better binding and more durable pellets at lower energy consumption. The overall objective of this study was to develop and demonstrate a high-moisture pelleting process using corn stover with the addition of a binder to produce good quality pellets in terms of green durability (after cooling) and cured durability (after drying) at a lower specific energy consumption. The specific objectives for the study were to 1$)$ conduct high-moisture pelleting of corn stover at different feedstock moisture contents $(33,36$, and $39 \%$, w.b.) and starch binder contents $(0,2$, and $4 \%), 2)$ evaluate the physical properties (pellet moisture content, pellet diameter, expansion ratio, bulk density and durability (green and cured durability), and 3) evaluate specific energy consumption of the pelleting process. 


\section{Protocol}

NOTE: Corn stover bales were procured in the form of bales from agricultural farms in lowa, USA. The procured bales were ground sequentially in two stages. In stage 1, the corn stover bales were ground using a grinder fitted with a $50.8-\mathrm{mm}$ screen. In stage 2 , the ground material from stage 1 was further ground by using a Bliss hammer mill fitted with a 4.8-mm screen. The material was tested for moisture content and bulk density and stored in an air tight container for further pelleting tests. Pure corn starch was procured from a local market and was measured for the moisture content and bulk density. The moisture content and bulk density of ground corn stover and corn starch binder are given Table 1.

\begin{tabular}{lll}
\hline Feedstock & Moisture content $(\%$, w.b. $)$ & Bulk density $\left(\mathrm{kg} / \mathrm{m}^{3}\right)$ \\
& & \\
\hline Ground corn stover (4.8 mm screen) & $8.39(0.03)$ & $111.0(2.3)$ \\
Corn starch binder (\%) & $9.72(0.02)$ & $597.1(31.3)$ \\
\hline
\end{tabular}

Table 1. Moisture content and bulk density of ground corn stover and corn starch binder.

\section{Pellet Mill}

1. Use a laboratory scale flat die pellet mill equipped with a $10 \mathrm{HP}$ motor for carrying out the pelleting tests (Figure 1$)^{21,28,38}$.

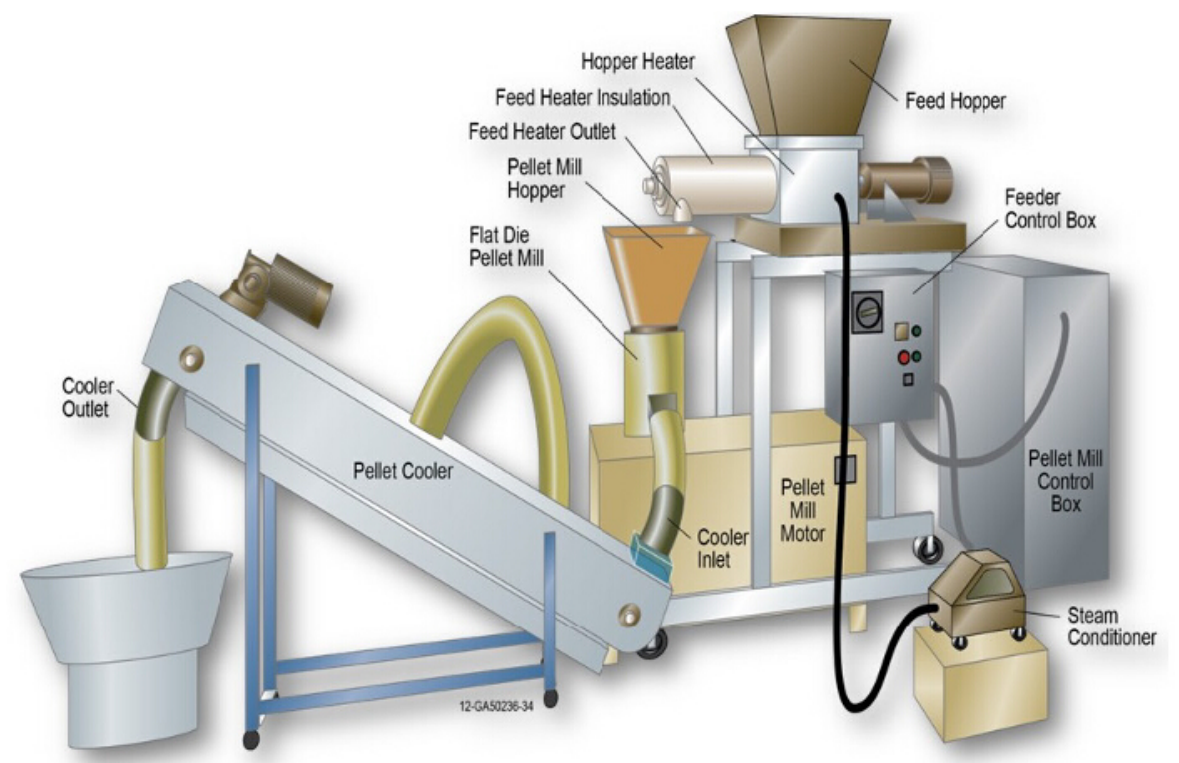

Figure 1. Schematic of a laboratory scale flat die pellet mill at Idaho National Laboratory (adapted from Tumuluru ${ }^{21}$ ). A flat die pellet mill was used to conduct the high moisture corn stover pelleting tests with and without binder addition. Please click here to view a larger version of this figure.

2. Place flexible heating tape on the surface of the hopper and screw feeder then insulate them with glass wool to prevent heat loss. Connect the heating tape to a temperature controller to preheat biomass to desired temperature in the range of $30-130{ }^{\circ} \mathrm{C}$.

3. Equip the pellet mill with a variable frequency drive (VFD). Connect the VFD of the pellet mill to the pellet mill motor. The feeder motor controller is a direct current motor controller to vary the feeding rate to pellet mill.

4. Connect a power meter to the pellet mill motor to record the power consumption. Manually choose a pellet die with an $8 \mathrm{~mm}$ diameter opening and a length to diameter (L/D) ratio of 2.6.

5. Add a horizontal pellet cooler to the pellet mill to cool the warm pellets coming out of the pellet die. Connect the cooler to an exhaust system to circulate fresh air.

\section{Feedstock Preparation}

1. Take $2-3 \mathrm{~kg}$ of corn stover ground using a $4.8 \mathrm{~mm}$ screen. Measure the corn stover moisture content (see step 4.1) and bulk density (see step 4.3) (see Table 2).

2. Measure moisture content (see step 4.1) and bulk density (see step 4.3$)$ of the pure $(100 \%)$ corn starch binder procured from the local market.

3. Add corn starch binder to the ground corn stover (see Table 2 for \% binder addition)

4. Calculate the amount of water to be added to adjust the moisture levels of ground corn stover and corn starch binder mix to 33 , 36 , and $39 \%$ (w.b.) using equation 1.

$W_{w}=W s \times\left(\frac{m_{f}-m_{i}}{100-m_{f}}\right)(1)$

NOTE: In equation $1, W_{w}$ is weight of water $(g), W_{s}$ is weight of biomass sample $(g), m_{f}$ : percent final moisture content of the sample (w.b.), and $\mathrm{m}_{\mathrm{i} \text { : }}$ percent initial moisture content of the sample (w.b. \%). 
5. Add the calculated water to the corn stover/corn starch binder mix and blend it in a laboratory scale ribbon blender.

6. Store the moisture-adjusted corn stover/corn starch mix in a sealed container and place it in a refrigerator set at $4-5{ }^{\circ} \mathrm{C}$ to allow moisture to equilibrate.

\section{High Moisture Pelleting Process}

1. Take the corn stover/corn starch mix out of refrigerator and leave it at room temperature for about 1-2 hr to bring it to room temperature.

2. Load the material into the feed hopper of the pellet mill. Run the pellet mill at $60 \mathrm{~Hz}(380 \mathrm{rpm})$ die speed.

3. Feed the pellet mill uniformly by adjusting the feeding rate of the pellet mill to produce pellets in a steady state condition. Cool the pellets in the horizontal pellet cooler.

4. Separate fines generated in the pelleting process using a $6.3 \mathrm{~mm}$ screen NOTE: Measure the moisture content and durability of the pellets after cooling ${ }^{21}$

5. Dry the cooled high-moisture pellets in a laboratory oven at $70^{\circ} \mathrm{C}$ for $3-4 \mathrm{hr}$ to reduce the final moisture content of the pellets to less than $9 \%$ (w.b.).

NOTE: Measure the pellet moisture content, bulk density, and durability of the dried pellets ${ }^{21}$.

6. Log the power data into a computer during the pelleting process. NOTE: See Table 2 for pelleting test conditions and Figure 2 for pellets produced at 33, 36 and 39\% moisture content and $4 \%$ corn starch binder addition.

\begin{tabular}{ll}
\hline Pelleting process variables \\
\hline Feedstock moisture content (\%, w.b.) & 33,36 , and 39 \\
Corn starch binder (\%) & 0,2 , and 4 \\
\hline
\end{tabular}

Table 2. Experimental test conditions used in the present study.

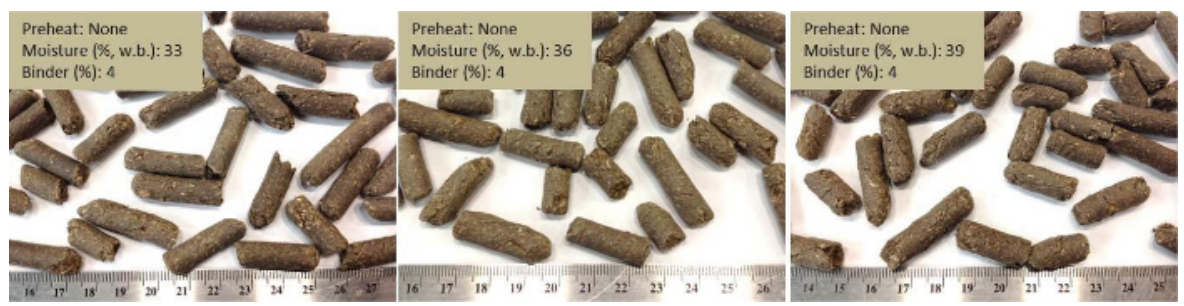

Figure 2. Photograph of the corn stover pellets produced with $4 \%$ corn starch binder at different feedstock moisture contents. Please click here to view a larger version of this figure.

\section{Pellet Properties and Specific Energy Consumption}

NOTE: ASABE standards ${ }^{42}$ were used for measuring the moisture content, density, durability and percent fines of raw and pelleted materials.

1. Place about $25-50 \mathrm{~g}$ of the ground and pelleted corn stover samples in a laboratory oven set at $105^{\circ} \mathrm{C}$ for $24 \mathrm{hr}$. Weigh the sample before and after drying. Calculate the moisture content using equation 2. Conduct the experiments in triplicate.

Moisture content $(\%, w . b)=.\frac{\text { Wet weight of the sample }(g) \text {-Weight of sample after drying }(g)}{\text { Wet weight of the sample }(g)} \times$ 100

2. Take a single pellet and smooth both the ends with Grit Utility Cloth. Measure the pellet diameter using Vernier calipers. Calculate the expansion ratio of the pellet using equation $3^{28}$. Measure the diameter of the ten pellets.

Expansion ratio $=\frac{\mathrm{D}^{2}}{\mathrm{~d}^{2}}(3)$

NOTE: In equation 3, $\mathrm{D}$ is the diameter of the pellet extruded $(\mathrm{mm})$ and $\mathrm{d}$ is the diameter of the die $(\mathrm{mm})$.

3. Use a plexi glass cylinder with a height of $155 \mathrm{~mm}$ and a diameter of $120 \mathrm{~mm}$. Pour the pellets into the cylinder until it overflows and level the top surface with a straight edge. Weigh the cylinder with the material. Divide the weight of the cylinder by the volume of the cylinder to calculate bulk density. Repeat the experiment three times.

4. Hand sieve the pelleted material using a $6.3 \mathrm{~mm}$ screen. Weigh the material that has passed through the screen. Calculate the percent fines using equation 4 .

Percent fines $=\frac{\text { Weight of material that has passed through } 6.2 \mathrm{~mm} \text { screen }}{\text { Weight of the pelleted sample }(\text { fines }+ \text { pellets })} \times 100(4)$

5. Place approximately $500 \mathrm{~g}$ of the pellets without fines into each compartment of the pellet durability tester. Tumble the pellets at 50 rev/min for $10 \mathrm{~min}$. Sieve the tumbled material using a $6.3 \mathrm{~mm}$ screen. Use equation 5 to calculate the percent durability of the pellets.

Durability $=\frac{\text { Weight of pellets after tumbling }}{\text { Weight of pellets before tumbling }} \times 100(5)$

Note: Green durability is the durability of the pellets measured after cooling, and cured durability is the durability measured after drying the pellets at $70{ }^{\circ} \mathrm{C}$ for $3 \mathrm{hr}$.

6. Log the pellet mill power consumption using data logging software. Record the no load power (kW) data of the pellet mill by running the pellet mill empty at $60-\mathrm{Hz}$ die speed. Use equation 6 to calculate the specific energy consumption (SEC).

$\mathrm{SEC}=\frac{\text { (Full load power }(\mathrm{kW}) \text {-No load power }(\mathrm{kW})) \times \text { time }(\mathrm{hr})}{\text { weight of biomass material }(\mathrm{kg})} \times 1000=\frac{\mathrm{kWhr}}{\text { ton }}(6)$ 


\section{Representative Results}

\section{Pellet Moisture Content}

The moisture content of the biomass was reduced by about 5-8\% (w.b.) after pelleting. This reduction is mainly attributed to frictional heat developed in the die, and preheating temperature and cooling of the high moisture pellets. Also, binders had an impact on the amount of moisture lost. At $0 \%$ binder, the loss of moisture was about $7-8 \%$, which agrees with our earlier studies ${ }^{21,28}$; whereas, at $4 \%$ binder, the loss of moisture in the feedstock during pelleting was about 3-5\% (Figure 3). The binder added to the biomass might have acted as a lubricating agent. This may have reduced the frictional resistances and reduced the residence time of the material in the die channel causing the decrease in moisture loss. In previous studies die temperature measured immediately after pelleting using an infrared thermometer (Fluke, Model 561, Fluke Corporation, Everett, WA, USA) reached to about $100-110^{\circ} \mathrm{C}^{21}$. Increasing the binder percentage reduced the moisture loss as the moisture might have been tightly bound to the starch granules. The high moisture pellets that were further dried in a laboratory oven at $70{ }^{\circ} \mathrm{C}$ for $3-4 \mathrm{hr}$ had moisture contents $<9 \%$ (w.b.), and these pellets were used to measure other physical properties like pellet diameter, expansion ratio, bulk density and durability. Statistical analysis of the pellet moisture content data indicated that there was an interactive effect of feedstock moisture content and binder addition on the pellet moisture content (Table 3). For pellets with no binder and $2 \%$ binder, an increase in feedstock moisture content caused an increase in pellet moisture content (Tukey's $p<0.05$ ), but this trend was not statistically significant at $4 \%$ binder (Tukey's $p \geq 0.05$; Figure 3).

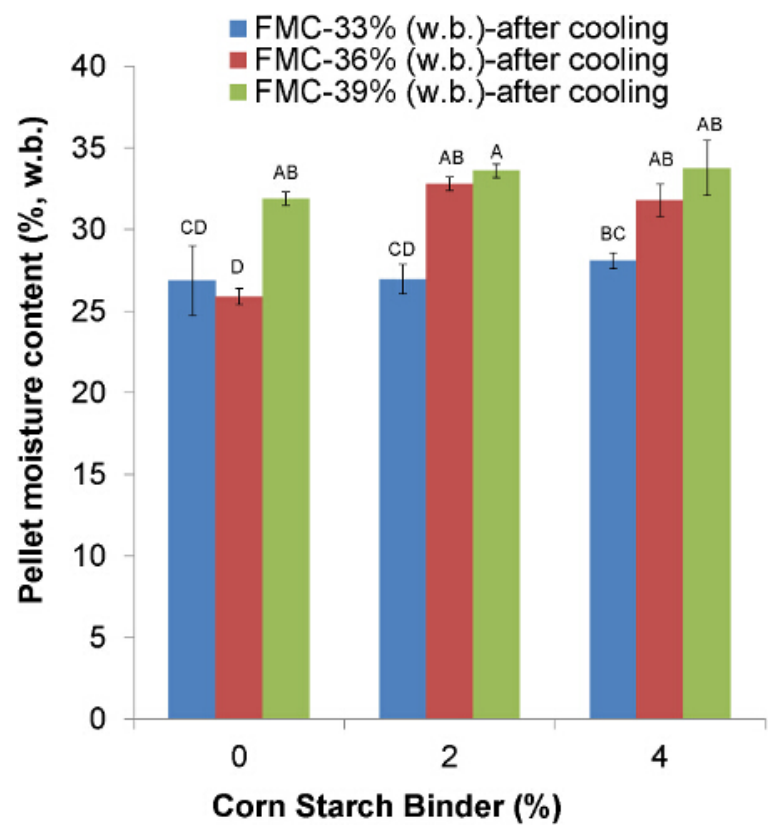

Figure 3. Effect of feedstock moisture content (FMC) and starch binder on pellet moisture content after cooling (mean $\pm 1 S D ; n=3$ ). Pelleting tests conducted without binder resulted in higher feedstock moisture content loss compared to tests conducted with binder. Different letters indicate significant differences using post hoc Tukey HSD tests $(p<0.05)$. Please click here to view a larger version of this figure.

\section{Pellet Diameter}

The diameter of the pellets at $33 \%$ moisture content with and without binder addition was in the range of 8.4-8.7 mm after cooling (data not shown). Increasing the feedstock moisture content to 36 and $39 \%$ (w.b.) with added binder increased the pellet diameter to a maximum value of $9.3 \mathrm{~mm}$ (data not shown). These pellets were further dried in a laboratory oven at $70^{\circ} \mathrm{C}$ for about $3-4 \mathrm{hr}$. Drying resulted in a decrease in pellet diameter of about $0.3-0.4 \mathrm{~mm}$. The major reason for a decrease in diameter after drying was due to contraction of the pellets. There was a statistically significant effect of the interaction between feedstock moisture content and binder addition on pellet diameter after drying (Table 3). At $33 \%$ feedstock moisture content the pellet diameter after drying was in the range of 8.3 to $8.5 \mathrm{~mm}$, whereas increasing the feedstock moisture content to $36 \%$ or $39 \%$ increased the pellet diameter to about $8.7 \mathrm{~mm}$ (Figure 4). This increase was only statistically significant between $33 \%$ and $39 \%$ when no binder was used (Tukey's $p<0.05$ ), likely because of the high deviations in the measurements. 


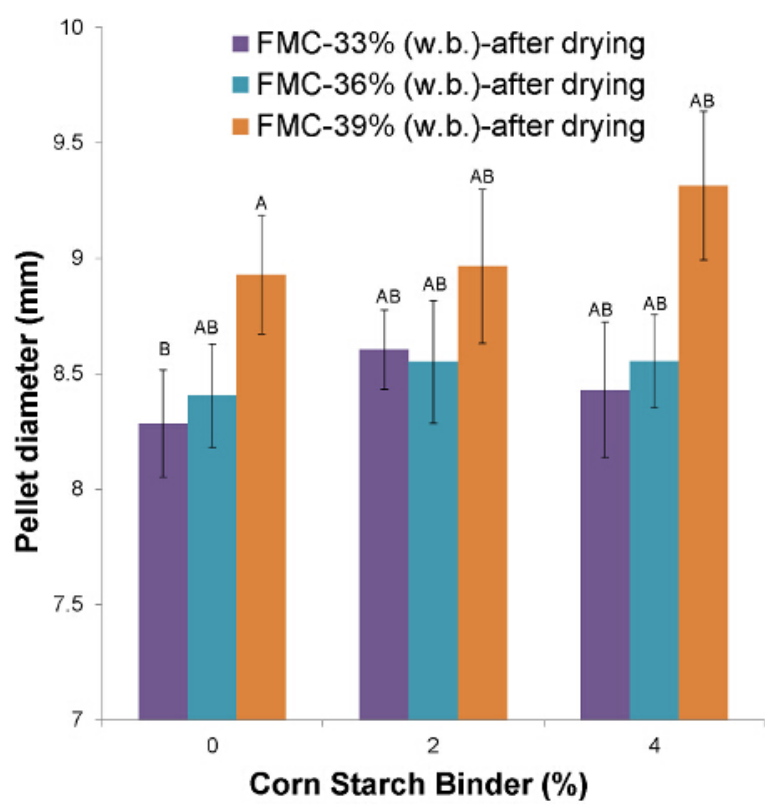

Figure 4. Effect of feedstock moisture content (FMC) and corn starch binder on pellet diameter after drying (mean $\pm 1 S D ; n=10)$. Pellet diameter increased with an increase in feedstock moisture content and starch addition. Different letters indicate significant differences using post hoc Tukey HSD tests $(p<0.05)$. Please click here to view a larger version of this figure.

\section{Expansion Ratio}

Expansion ratio is calculated using the pellet diameter (equation 3). The expansion ratio values were higher for the pellets after cooling compared to after drying (data not shown). At 33\% moisture content without and with binder addition, the expansion ratio values after cooling were in the range of 1.16-1.20. Further increasing the moisture content to 36 and $39 \%$ without binder addition increased the expansion ratio values to 1.35. The dried pellets had lower expansion ratios, which was mainly due to contraction of the pellets both diametrically and laterally. At $33 \%$ feedstock moisture content the expansion ratio values with and without binder addition were in the range of 1.11-1.07 (Figure 5). Increasing the feedstock moisture content to 36 and 39\% further increased the expansion ratio values to 1.10-1.18 (Figure 5); however, this was only statistically significant for $33 \%$ compared to $39 \%$ moisture content with no binder addition (Tukey's $p<0.05$; Table 3 ). In the case of pellet diameter and expansion ratio, adding a starch based binder increased these values at all of the feedstock moisture contents, but these differences were not statistically significant (Tukey's $p \geq 0.05$ ). The expansion ratio results after drying corroborate the findings of earlier studies, where increasing feedstock moisture increased the expansion ratio and further decreased the bulk density values ${ }^{28}$.

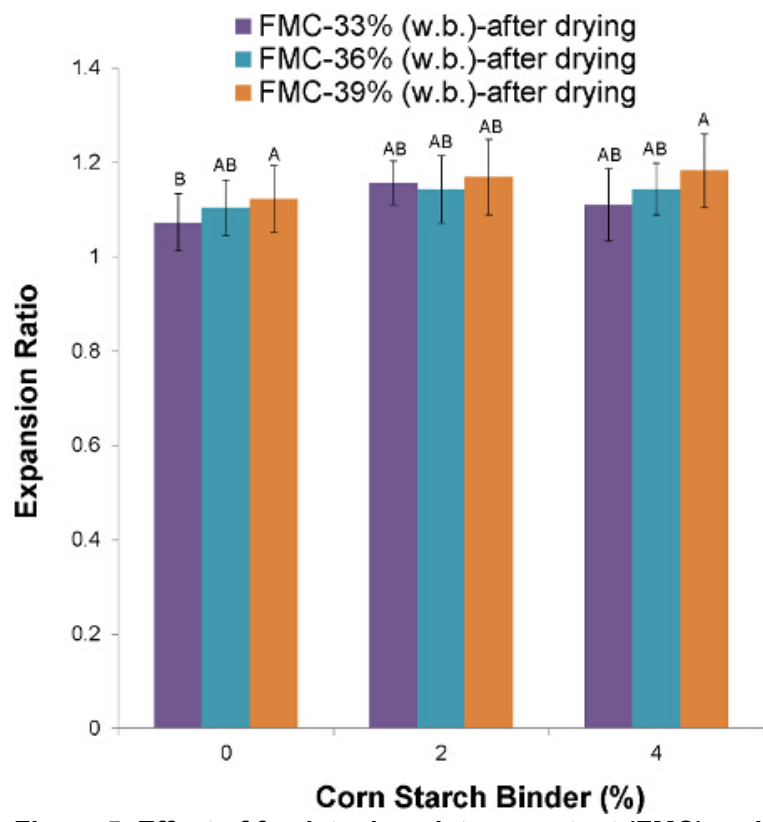

Figure 5. Effect of feedstock moisture content (FMC) and starch based binder on the expansion ratio of pellets after drying ( $\mathrm{n}=10$ ). Expansion ratio of pellets increased with an increase in feedstock moisture content without and with binder addition. Different letters indicate significant differences using post hoc Tukey HSD tests $(p<0.05)$. Please click here to view a larger version of this figure. 


\section{Bulk Density}

The bulk density of the pellets made with a feedstock moisture content of $33 \%$ with and without binder and measured after cooling was in the range of $464-514 \mathrm{~kg} / \mathrm{m}^{3}$ (data not shown). At 36 and $39 \%$ feedstock moisture content without binder the bulk density values were in the range of $437-442 \mathrm{~kg} / \mathrm{m}^{3}$. Adding binder at these feedstock moisture contents reduced bulk density to $<400 \mathrm{~kg} / \mathrm{m}^{3}$. Drying the high-moisture pellets in a laboratory oven at $70{ }^{\circ} \mathrm{C}$ for about 3 hours reduced the moisture contents of the pellets to less than $9 \%$ (w.b.). There was a slight increase in the bulk density values by about $50 \mathrm{~kg} / \mathrm{m}^{3}$ after drying. The increase in bulk density after drying could be due to fewer inter-particle liquid bridges, which might have kept the particles closer with less-open structure. Oginni ${ }^{44}$ observed that the bulk density of ground Loblolly pine decreased with an increase in moisture content. For pellets made with a feedstock moisture content of $33 \%$ with and without the binder addition, the bulk density of the pellets was in the range of $520-530 \mathrm{~kg} / \mathrm{m}^{3}$ (Figure 6). At higher feedstock moisture contents of 36 and $39 \%$ (w.b.), the bulk density of the dried pellets significantly decreased to $<434 \mathrm{~kg} / \mathrm{m}^{3}$ and $<437 \mathrm{~kg} / \mathrm{m}^{3}$, respectively. There was a statistically significant effect of the interaction between feedstock moisture content and binder addition on bulk density (Table 3 ). In general, bulk density decreased with an increase in starting feedstock moisture content. In addition, there is some indication that bulk density decreased with an increase in starch content (Figure 6).

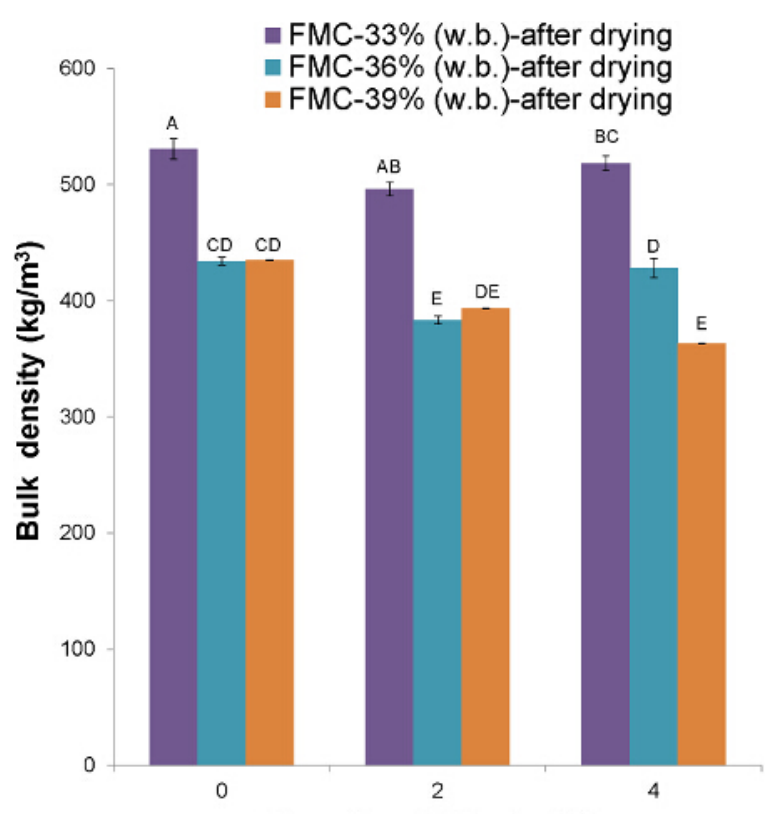

Corn Starch Binder (\%)

Figure 6. Effect of feedstock moisture content (FMC) and starch binder on the bulk density of pellets after drying (mean $\pm 1 S D ; n=3$ ). Lower feedstock moisture content of 33\% (w.b.) and no binder resulted in the highest bulk density. Adding 2 and $4 \%$ binder at different feedstock moisture contents resulted in lower bulk density values. Different letters indicate significant differences using post hoc Tukey HSD tests ( $p<0.05$ ). Please click here to view a larger version of this figure.

\section{Durability (\%)}

\section{After Cooling}

\section{Green Durability}

Figure 7 shows the durability of pellets after cooling (green strength) and after drying in an oven at $70{ }^{\circ} \mathrm{C}$ for $3-4$ hours (cured strength). Higher durability values of high moisture pellets are desirable as it will result in less breakage during handling and storage due to shear and impact resistances. For the ANOVA, the interaction was significant between feedstock moisture content, binder percent, and drying (Table 3). The durability values of the pellets after cooling increased with an increase in binder content (Table 3; Tukey's p<0.05). At 33\% (w.b.) feedstock moisture content, the durability values without binder were about $87.2 \%$; whereas, with the addition of a 2 and $4 \%$ starch binder, the durability values increased to 93.2 and $96.1 \%$ (Figure 7). The trend was similar for the other feedstock moisture contents of 36 and $39 \%$ (w.b.). Without binder the durability values were about $80 \%$; however, adding binder to the biomass increased the durability values. The durability increased to about $90 \%$ when pellets were made with a feedstock moisture content of $36 \%$ and $4 \%$ starch binder. At even higher feedstock moisture content of $39 \%$ (w.b.) the trend was similar, but the overall durability values decreased compared to the other feedstock moisture contents. 
m FMC-33\% (w.b.)-after cooling $=$ FMC-36\% (w.b.)-after cooling

$=$ FMC-39\% (w.b.)-after cooling $=$ FMC-33\% (w.b.)-after drying

aMC-36\% (w.b.)-after drying $=$ FMC-39\% (w.b.)-after drying

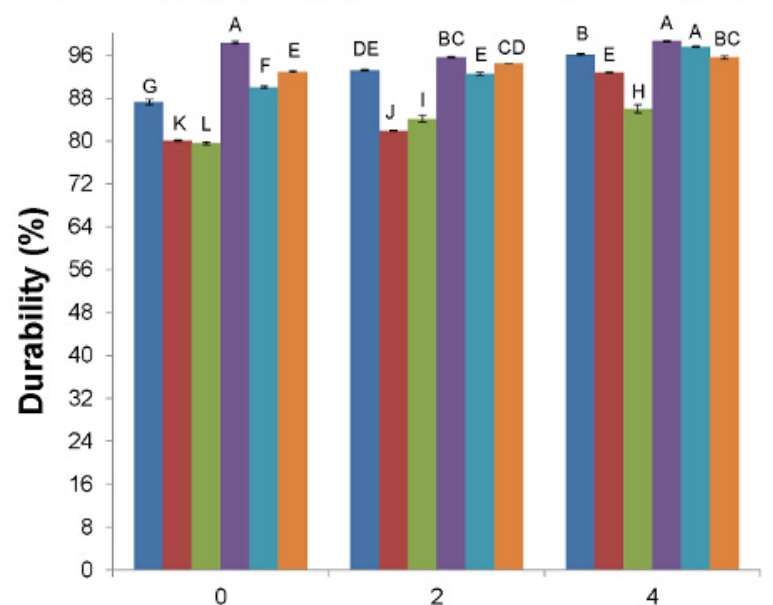

2

4

Corn Starch Binder (\%)

Figure 7. Effect of feedstock moisture content (FMC) and starch binder on durability after cooling and after drying (mean \pm 1 SD; $n=3$ ). Durability values of high moisture corn stover pellets produced at 33, 36 and $39 \%$ (w.b.) feedstock moisture content increased with binder addition both after cooling and after drying. Different letters indicate significant differences using post hoc Tukey HSD tests $(p<0.05)$. Please click here to view a larger version of this figure.

\section{After Drying}

\section{Cured Durability}

Drying of the high-moisture pellets in a laboratory oven at $70{ }^{\circ} \mathrm{C}$ for $3-4$ hours resulted in curing of the pellets, thereby increasing the durability of the pellets. The durability values of the pellets made at 33, 36 and $39 \%$ (w.b.) feedstock moisture content increased to $>92 \%$ (Figure 7 ). The durability values at $33 \%$ feedstock moisture content increased to about $98 \%$ after drying (Figure 7). These results match closely with earlier work $^{21,28}$. The durability values of the pellets made using a binder increased after drying (Tukey's $p<0.05$ ). At $33 \%$ feedstock moisture content and $4 \%$ binder, the final durability values observed were about $98 \%$. The trend was similar at 36 and $39 \%$ feedstock moisture content, where the binder had a positive impact on the durability values (Tukey's $p<0.05$ ). At $39 \%$ feedstock moisture content with a binder addition of 2 and $4 \%$, the durability values increased to about $94-95 \%$.

\section{Percent Fines}

In the present study, the percent fines generated during pelleting were higher at 36 and $39 \%$ (w.b.) compared to $33 \%$ (w.b.) feedstock moisture content. Adding binders resulted in lowering the percent fines generated at all feedstock moisture contents when compared to tests with no binder addition (Figure 8). Pelleting tests conducted with no binder showed the highest percent fines of about $11 \%$ at $39 \%$ (w.b.) feedstock moisture content. Adding 2 and $4 \%$ binder to the corn stover, decreased the percent fines generated during pelleting for $33 \%$ and $36 \%$ (w.b.) compared to pellets with no binder added. The lowest percent fines observed in this study were at $4 \%$ binder addition and $33 \%$ (w.b.) feedstock moisture content (approximately $3 \%$ ). 


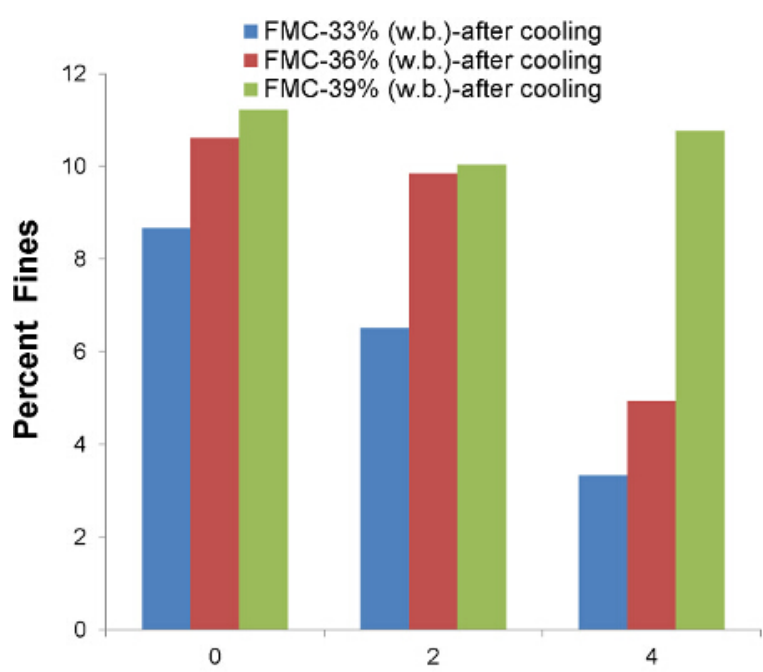

Corn Starch Binder (\%)

Figure 8. Effect of feedstock moisture content and starch binder on the percent fines produced from the pelleted material. At feedstock moisture contents of 33, 36 and $39 \%$ (w.b.) addition of binder reduced the percent fines in the pelleted material. Please click here to view a larger version of this figure.

\section{Specific Energy Consumption}

The specific energy consumption was influenced by binder addition (Figure 9). With no binder, the specific energy at 33, 36, and 39\% feedstock moisture content was between 118-126 kWhr/ton. Adding a $2 \%$ binder reduced the specific energy consumption to about $75-94 \mathrm{kWhr} / \mathrm{ton}$. Further increasing the binder percentage to $4 \%$ further reduced the specific energy consumption to about $68-75 \mathrm{kWhr} / \mathrm{ton}$ for all feedstock moisture contents that were tested. Adding the binder at 2 and $4 \%$ reduced the specific energy consumption by about $20-40 \%$.

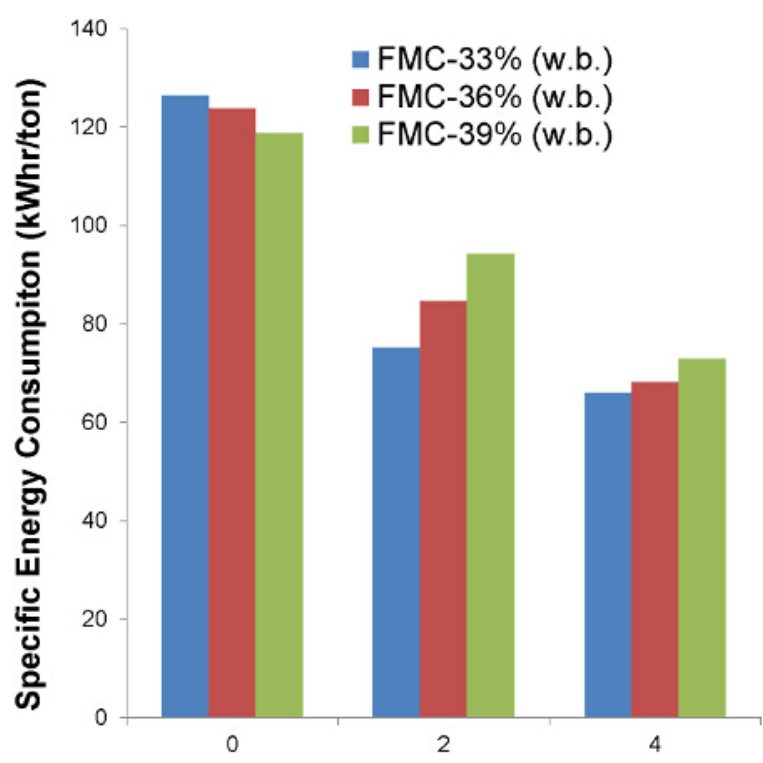

Corn Starch Binder (\%)

Figure 9. Effect of feedstock moisture content and starch binder on the specific energy consumption of the high moisture pelleting process. Specific energy consumption of the high moisture corn stover pelleting process was reduced by about $20-40 \%$ with addition of 2 and $4 \%$ starch based binder. Please click here to view a larger version of this figure.

\section{Statistical Analysis}

Statistical analysis was completed in JMP $10^{43}$. A two-way ANOVA was used to determine the effects of feedstock moisture content (33, 36, $39 \%)$ and corn starch binder $(0,2,4 \%)$ on pellet moisture content $(n=3)$, pellet diameter $(n=10)$, expansion ratio $(n=10)$, and bulk density $(n=3)$. A three-way ANOVA was used to determine the effects of moisture content $(33,36,39 \%)$, corn starch binder $(0,2,4 \%)$, and drying (before drying, after drying) on durability ( $n=3)$. Residuals met the ANOVA assumptions for normality and homogeneity of variance. To meet these assumptions, pellet moisture content was transformed by raising the data to the $4^{\text {th }}$ power. If the factors tested in the ANOVA were significant at $p<0.05$, Tukey HSD tests were used for post hoc pairwise comparisons. 


\begin{tabular}{|c|c|c|c|c|c|}
\hline \multirow[t]{2}{*}{ Source of Variation } & \multicolumn{5}{|c|}{ Measured Values } \\
\hline & Moisture Content & Bulk Density & Durability & Diameter & $\begin{array}{l}\text { Expansion } \\
\text { Ratio }\end{array}$ \\
\hline $\begin{array}{l}\text { Feedstock Moisture Content } \\
\text { (FMC) }\end{array}$ & $<0.0001$ & $<0.0001$ & $<0.0001$ & 0.0464 & 0.0184 \\
\hline Binder & 0.0002 & $<0.0001$ & $<0.0001$ & 0.3833 & 0.1893 \\
\hline Drying & NA & NA & $<0.0001$ & NA & NA \\
\hline FMC*Binder & 0.0019 & 0.0022 & $<0.0001$ & 0.0240 & 0.0405 \\
\hline FMC*Drying & NA & NA & $<0.0001$ & NA & NA \\
\hline Binder*Drying & NA & NA & $<0.0001$ & NA & NA \\
\hline FMC*Binder*Drying & NA & NA & $<0.0001$ & NA & NA \\
\hline
\end{tabular}

Table 3. Statistical significance of the process variables based on analysis of variance (ANOVA).

\section{Discussion}

The critical steps in the high moisture pelleting method to produce pellets with the desired durability at lower specific energy consumption are: 1) drying the high moisture corn stover to the desired moisture levels (33-39\%, w.b.), 2) percent binder addition and 3) feeding high moisture biomass uniformly into the pellet mill. Feedstock moisture and percent binder are process variables that influenced the pellet properties (density and durability of the pellets before cooling and after drying) and specific energy consumption of the pelleting process. It is recommended to test the moisture content of the feedstock before it is used for pelleting studies. Feeding of high moisture corn stover at 33,36 and $39 \%$ (w.b.) uniformly to the pellet mill has an impact on quality and energy consumption. Modifying the pellet mill feeder with a variable frequency drive was essential to feed the biomass uniformly to the pellet mill.

Results from the present study indicated that adding binder to the high moisture corn stover did reduce the bulk density of the pellets marginally, but improved the durability significantly. Adding a starch based binder increased the moisture content in the pellets after compression and extrusion, but the increase was found not to be statistically significant in almost all the cases studied. The loss of moisture during pelleting was about 3 to $4 \%$ at the addition of $4 \%$ binder, whereas it was higher (7-8\%, w.b.) without the binder. The addition of a binder to the corn stover might have 1) reduced the residence time of the material in the die and 2) reduced the frictional resistances in the die, thereby reducing the die temperature, which might have resulted in less moisture loss during compression and extrusion in the pellet die.

There was an increase in the pellet diameter after it was extruded from the pellet die and dried (Figure 4). This increase was greater at higher feedstock moisture content and with starch binder addition. The bulk density of the pellets was in the range of $510-530 \mathrm{~kg} / \mathrm{m}^{3}$ at $33 \%$ (w.b.) feedstock moisture content with and without a binder. Previous research has indicated that higher feedstock moisture content of about $38 \%$ (w.b.) results in lower bulk density, mainly due to expansion of the pellets as they exit through the die ${ }^{21,28}$. It is a common phenomenon that when high-moisture biomass material is extruded through the die under pressure it results in moisture flash-off ${ }^{i 2,21}$. The moisture flash-off gives way to the expansion of the pellet, both in the axial and diametrical direction. In general, the diametrical expansion is more prominent compared to axial expansion. Another reason for the expansion behavior of biomass after compression and extrusion through the pellet die could be that biomass fibers relax in the presence of moisture content. Ndiema et al. ${ }^{45}$ and Mani et al. ${ }^{18}$ indicated that release of the applied pressure in a die results in relaxation of the compressed biomass. The relaxation characteristics are dependent on many factors like particle size, feedstock moisture content and applied pressure. Also, in this study we have observed that the bulk density increases after drying, which could be due to fewer inter-particle liquid bridges that might have kept the particles closer and produced a less-open structure. Oginni ${ }^{45}$ observed that the bulk density of ground Loblolly pine decreased with increased moisture content.

Durability of the pellets was measured to understand the strength of the pellets. Generally, pellets are subject to shear and impact resistances during storage, transportation, and the handling process ${ }^{4,46}$. Kaliyan and Morey ${ }^{47}$ suggested that durability of pellets produced immediately after production (green strength) is different than durability of the pellets that are stored for a few days after production (cured strength). Pellets with lower durability values break and increase the risk of storage issues, such as off-gassing and spontaneous combustion that could cause revenue loss for pellet manufacturers. According to the European Committee for Standardization (CEN) and the United States Pellet Fuels Institute (PFI) the recommended values of the durability are $>96.5 \%$ for high quality or premium grade pellets ${ }^{31}$. In this study, the durability values increased to approximately $94-95 \%$ when pelleted with a starch binder at $39 \%$ moisture content compared to pellets made with no binder that had durability values in the range of $83-85 \%$ after drying. The pellets produced at $33 \%$ (w.b.) feedstock moisture content had durability values $>96.5 \%$ and meet the international standards.

Moisture has different functions during biomass pelleting, including: 1) solid bridge formation between the biomass particles due van der Waals forces, 2) activating natural binders like protein, starch and lignin present in the biomass, and 3) promoting starch and protein based reactions like gelatinization and denaturation that have a strong impact on the textural properties, such as hardness ${ }^{4-12}$. In the case of lignocellulosic biomass, the main binding agent is lignin (woody biomass: $27-33 \%$, herbaceous biomass: $12-16 \%)^{4}$. Lignin content in corn stover was determined to average around $16 \%$ based on a review of composition data, including literature sources and feedstock databases ${ }^{48}$. Lignin molecules, which have higher mobility at higher moisture content, act as an adhesive and result in stronger binding; however, at very high levels the moisture will act more like a lubricant resulting in less binding. In the present study, at a very high moisture content of about $39 \%$ (w.b.) moisture might have acted more like a lubricant and resulted in low durability and more fines generation in the pellet production process. Higher durability values were observed by the addition of a binder at a higher feedstock moisture content of 36 and $39 \%$ (w.b.), which could be caused by gelatinization of starch in the presence of die temperature and feedstock moisture content. These gelatinization reactions can lead to the formation of cross linking of starch with the other biomass components.

The percent fines generated during the pelleting process is a good indicator for how well biomass will form pellets. Generation of fine particles during the pelleting process results in product and revenue loss to the pellet producer. Excessive fine generation during pelleting processes can also have an impact on quality attributes such as density and durability. The fines generation during the pellet production process is influenced by biomass composition (i.e., starch, protein, lignin, and waxes), pellet mill process variables i.e., length to diameter ratio (L/D ratio), die rotational speed, steam condition, preheating), and feedstock variables (i.e., feedstock moisture content, particle size and feed rate) ${ }^{4}$. The present results 
indicate that the addition of binder not only reduces the percent of fine particles generated, but also helps to improve the physical properties while reducing the specific energy consumption. Lower percent fines generated indicate that the biomass has a greater pelletability.

Tumuluru et al. ${ }^{4}$ in their review on densification systems suitable to make biomass into a commodity type product indicated that adding binder helps to reduce the extrusion energy, which results in reducing the specific energy consumption. Typically, length to diameter (L/D) ratio controls the residence time of the material in the die and helps the binding of the biomass. Also, L/D ratio controls the extrusion energy and the specific energy consumption. Higher L/D ratio increases the residence time, which improves the physical properties of the pellets, but increases the energy necessary for extrusion. Adding a binder to biomass can help bind the biomass at lower L/D ratio and reduce the extrusion energy. In this study, a constant length to diameter (L/D) ratio of (2.6) was selected. Future research is aimed at understanding the effect of L/D ratio of the pellet die and its interaction with feedstock moisture content on pellet quality attributes.

The experimental data on biomass preprocessing (grinding, drying and pelleting) obtained from the Biomass National User Facility (https:// www.inl.gov/bfnuf/) located at INL and associated techno-economic analysis indicated that drying biomass from 30-10\% (w.b.) consumes a large amount of energy (unpublished data). The high moisture pelleting process developed at INL can help reduce the pellet production cost compared to a conventional pellet production method ${ }^{24}$. The present study indicated that adding a starch-based binder to a high moisture pelleting process improved the durability of the pellets to $>92 \%$ after cooling at the feedstock moisture contents of 36 and $39 \%$ (w.b.), and it also reduced the specific energy consumption of the pelleting process by about $20-40 \%$. Greater durability values of the pellets made at higher feedstock moisture is important as they can be handled efficiently by conveyors. Typically low durability pellets crumble to fines during handling and storage, which results in revenue loss for the pellet producers. In addition, fines generated in the process can result in safety hazards like spontaneous combustion and off-gassing ${ }^{28,41}$. The specific energy reduction by approximately $20-40 \%$ using a binder outweighs the cost of the binder. Also, based on this study we can conclude that some of the by-products from food processing industries could be used for biomass pelleting for bioenergy applications. Currently, the high-moisture pelleting process was demonstrated using a laboratory scale flat die pellet mill. The protocol described here for the laboratory-scale pellet mill will be the basis for developing scale-up models and for testing the process in pilot-scale and commercial-scale pellet mills.

\section{Disclosures}

No competing financial interests exist. This information was prepared as an account of work sponsored by an agency of the U.S. government Neither the U.S. government nor any agency thereof, nor any of their employees, makes any warranty, express or implied, or assumes any legal liability or responsibility for the accuracy, completeness, or usefulness of any information, apparatus, product, or process disclosed, or represents that its use would not infringe privately owned rights. References herein to any specific commercial product, process, or service by trade name, trademark, manufacturer, or otherwise, do not necessarily constitute or imply its endorsement, recommendation, or favouring by the U.S. government or any agency thereof. The views and opinions of the authors expressed herein do not necessarily state or reflect those of the U.S. government or any agency thereof.

\section{Acknowledgements}

The authors would like to acknowledge Matt Dee for supporting the experimental work, Matthew Anderson and Rod Shurtliff for instrumenting the pellet mill. This work was supported by the Department of Energy, Office of Energy Efficiency and Renewable Energy under the Department of Energy Idaho Operations Office Contract DE-AC07-05ID14517. Accordingly, the publisher, by accepting the article for publication, acknowledges that the U.S. government retains a nonexclusive, paid-up, irrevocable, worldwide license to publish or reproduce the published form of this manuscript, or allow others to do so, for U.S. government purposes.

\section{References}

1. Bapat, D.W., Kulkarni, S.V., \& Bhandarkar, V.P. Design and operating experience on fluidized bed boiler burning biomass fuels with high alkal ash. In: Proceedings of the 14th International Conference on Fluidized Bed Combustion. ASME Publishers, New York, NY, 165-174 (1997).

2. Sokhansanj, S., \& Fenton, J. Cost benefit of biomass supply and preprocessing: BIOCAP (Canada) research integration program synthesis paper. http://www.biocap.ca/rif/reprt/Sokhansanj_S.pdf, (2011).

3. Mitchell, P., Kiel, J., Livingston, B., \& Dupont-Roc, G. Torrefied biomass: A foresighting study into the business case for pellets from torrefied biomass as a new solid fuel. In: All Energy 2007. University of Aberdeen, ECN, Doosan Babcock, and ITI Energy (2007).

4. Tumuluru, J.S., Wright, C.T., Hess, J.R., \& Kenney, K.L. A review of biomass densification systems to develop uniform feedstock commodities for bioenergy application. Biofuels, Bioprod. Biorefin. 5, 683-707 (2011).

5. Tumuluru, J.S., Igathinathane, C., \& Archer, D. Energy analysis and break-even distance of transportation for biofuels in comparison to fossil fuels. ASABE Paper No. 152188618, 2015 ASABE Annual International Meeting, New Orleans, Louisiana, USA, July 26-29 (2015).

6. Searcy E.M., Hess J.R., Tumuluru J.S., Ovard, L., Muth, D.J., Jacobson, J., et al. Optimization of biomass transport and logistics. In: International Bioenergy Trade. Goh, M., Sheng, C., \& Andre, F., eds., Springer Publications, 103-123 (2013).

7. Ray, A., Hoover, A.N., Nagle, N., Chen, X., \& Gresham, G. Effect of pelleting on the recalcitrance and bioconversion of dilute-acid pretreated corn stover under low - and high - solids conditions. Biofuels. 4 (3), 271-284 (2013).

8. Sarkar, M., Kumar, A., Tumuluru, J.S., Patil, K.N., \& Bellmer, D.D. Gasification performance of switchgrass pretreated with torrefaction and densification. Appl. Energ. 127, 194-201 (2014).

9. Yang, Z., Sarkar, M., Kumar, A., Tumuluru, J.S., \& Huhnke, R.L. Effects of torrefaction and densification on switchgrass pyrolysis products Bioresource Technol. 174, 266-273 (2014).

10. Mani, S., Tabil, L.G., \& Sokhansanj, S. An overview of compaction of biomass grinds. Powder Handling Process. 15 (3), $160-168$ (2003).

11. Thomas, M., van Vliet, T., \& van der Poel, A.F.B. Physical quality of pelleted animal feed, part 3: Contribution of feedstuff components. Anim. Feed Sci. Technol. 70, 59-78 (1998). 
12. Shankar, T.J., \& Bandyopadhyay, S. Process variables during single-screw extrusion of fish and rice-flour blends. J. Food Process. Pres. 29, 151-164 (2004).

13. Collado, L.S., \& Corke, H. Starch properties and functionalities. In: Characterization of cereals and flours: properties, analysis, and applications. Kaletunç, G., \& Breslauer, K.J., eds., Marcel Dekker, Inc., 473-506 (2003).

14. Alebiowu, G., \& Itiola, O.A. Compression characteristics of native and pregelatinized forms of sorghum, plantain, and corn starches and the mechanical properties of their tablets. Drug Dev. Ind. Pharm. 28 (6), 663-672 (2002).

15. Sokhansanj, S., Mani, S., Bi, X., Zaini, P., \& Tabil, L.G. Binderless pelletization of biomass. ASAE Paper No. 056061, ASAE Annual International Meeting, Tampa, FL, USA, July 17-20, 2005. ASAE, St Joseph, Michigan, USA (2005).

16. Briggs, J.L., Maier, D.E., Watkins, B.A., \& Behnke, K.C. Effects of ingredients and processing parameters on pellet quality. Poult. Sci. 78 1464-1471 (1999).

17. Tabil, L.G. Binding and pelleting characteristics of alfalfa. Ph.D. dissertation. Department of Agricultural and Bioresource Engineering, University of Saskatchewan, Canada (1996).

18. Mani, S., Tabil, L.G., \& Sokhansanj, S. Specific energy requirement for compacting corn stover. Bioresource Technol. 97, 1420-1426 (2006).

19. Tumuluru, J.S., Tabil, L.G., Song, Y., Iroba, K.L., \& Meda, V. Impact of process conditions on the density and durability of wheat, oat, canola and barley straw briquettes. BioEnergy Res. 8 (1), 388-401 (2015).

20. van Dam, J.E.G., van den Oever, M.J.A., Teunissen, W., Keijsers, E.R.P., \& Peralta, A.G. Process for production of high density/high performance binderless boards from whole coconut husk, part 1: Lignin as intrinsic thermosetting binder resin. Ind. Crops Prod. 19 (3), 207-216 (2004).

21. Tumuluru, J.S. Effect of process variables on the density and durability of the pellets made from high moisture corn stover. Biosystems Eng. 119, 44-57 (2014).

22. Lehtikangas, P. Quality properties of fuel pellets from forest biomass. Licentiate Thesis. Report number 4. Department of Forest Management and Products, Uppsala, Sweden (1999).

23. Shinners, K.J., Boettcher, G.C., Hoffman, D.S., Munk, J.T., Muck, R.E., and Weimer, P.J. Single-pass harvesting of corn grain and stover: Performance of three harvester configurations. Transactions of the ASABE. 52 (1), 51-60 (2009).

24. Lamers, P., Roni, M.S., Tumuluru, J.S., Jacobson, J.J., Cafferty, K.G., Hansen, J.K., et al. Technoeconomic analysis of decentralized biomass processing depots. Bioresource Technol. 194, 205-213 (2015).

25. Yancey, N.A., Tumuluru, J.S., \& Wright, C.T. Drying, grinding and pelletization studies on raw and formulated biomass feedstock's for bioenergy applications. J. Biobased Mater. Bioenergy. 7, 549-558 (2013).

26. Tumuluru, J.S., Cafferty, K.G., \& Kenney, K.L. Techno-economic analysis of conventional, high moisture pelletization and briquetting process. American Society of Agricultural and Biological Engineer Annual Meeting, Paper No. 141911360, Montreal, Quebec Canada July 13 -16 (2014).

27. McCoy, G. Improving energy efficiency through biomass drying. International District Energy Association Woody Biomass CHP \& District Energy Workshop. Seattle, Washington, June 11 ${ }^{\text {th }}, 2014$, http://www.districtenergy.org/assets/pdfs/2014-Annual-Seattle/ Wednesday/5McCOYGIL-LATESTWoody-Biomass-Drying-and-Dewatering-IDEA-06-2014.pdf (page accessed on December $3^{\text {rd }}$, 2015) (2015).

28. Tumuluru, J.S. High moisture corn stover pelleting in a flat die pellet mill fitted with a $6 \mathrm{~mm}$ die: physical properties and specific energy consumption. Energy Sci. Eng. 3 (4), 327-341 (2015).

29. Brackley, A.M., \& Parrent, D.J. Production of wood pellets from Alaska-grown white spruce and hemlock. Pacific Northwest Research Station, Portland, OR, U.S.A.: U.S. Department of Agriculture, Forest Service Department. General Technical Report PNW-GTR-845. (2011).

30. Demirbas, A., \& Sahin-Demirbas, A. Briquetting properties of biomass waste materials. Energy Sources. 26, 83-91 (2004).

31. Kaliyan, N., \& Morey, R.V. Densification characteristics of corn stover and switchgrass. Transactions of ASABE. 52 (3), $907-920$ (2009).

32. Larsson, S.H., Thyrel, M., Geladi, P., \& Lestander, T.A. High quality biofuel pellet production from pre-compacted low density raw materials. Bioresource Technol. 99, 7176-7182 (2008).

33. Li, Y., \& Liu, H. High-pressure densification of wood residues to form an upgraded fuel. Biomass and Bioenergy. 19, 177-186 (2000).

34. Nielsen, N.P.K., Gardner, D.J., Poulsen, T., \& Felby, C. Importance of temperature, moisture content, and species for the conversion process of wood residues into pellets. Wood and Fiber Science. 41 (4), 414-425, (2009).

35. Serrano, C., Monedero, E., Laupuerta, M., \& Portero, H. Effect of moisture content, particle size and pine addition on quality parameters of barley straw pellets. Fuel Processing Technology. 92, 699-706 (2011).

36. Zafari, A., \& Kianmehr, M.H. Factors affecting mechanical properties of biomass pellets from compost. Environ. Technol. 35, 478-486 (2013).

37. Poddar, S., Kamruzzaman, M., Sujan, S.M.A., Hossain, M., Jamal, M.S., Gafur, M.A., \& Khanam, M. Effect of compression pressure on lignocellulosic biomass pellet to improve fuel properties: Higher heating value. Fuel. 131, $43-48$ (2014).

38. Hoover, A.N., Tumuluru, J.S., Teymouri, F., Moore, J., \& Gresham, G. Effect of pelleting process variables on physical properties and sugar yields of ammonia fiber expansion (AFEX) pretreated corn stover. Bioresource Technol. 164, 128-135 (2014).

39. Tumuluru, J. S., Tabil, L., Opoku, A., Mosqueda, M. R., \& Fadeyi, O. Effect of process variables on the quality characteristics of pelleted wheat distiller's dried grains with solubles. Biosystems Engineering. 105, 466-475 (2010).

40. Tumuluru, J. S. and Conner C. 2015. Specific energy consumption and quality of wood pellets producing using high moisture lodgepole pine. $7^{\text {th }}$ International Granulation Workshop, University of Sheffield, Sheffield, UK, $1^{\text {st }}-3^{\text {rd }}$ (https://www.sheffield.ac.uk/polopoly_fs/1.472578!/ file/2015_abstract_list_granulation_workshop.pdf) July, (2015).

41. Tumuluru, J.S., Sokhansanj, S., Lim, C.J., Bi, X.T., Lau, A.K., Melin, S., et al. Quality of wood pellets produced in British Columbia for export. Appl. Eng. Agric. 26, 1013-1020 (2010).

42. ABABE Standards. S269.4. Cubes, pellets, and crumbles - definitions and methods for determining density, durability, and moisture content. ASABE, St. Joseph, Missouri (2007).

43. JMP 10.0.0. from SAS Institute, Inc., Cary, North Carolina, USA (www.jmp.com) (2016).

44. Oginni, O.J. Contribution of particle size and moisture content to flowability of fractioned ground loblolly pine. M.S. Thesis. Submitted to Auburn University (2014).

45. Ndiema, C.K.W., Manga, P.N., \& Ruttoh, C.R. Influence of die pressure on relaxation characteristics of briquetted biomass. Energy Conversion and Management. 43, 2157-2161 (2002).

46. Al-Widyan, M.I., Al-Jalil, H.F., Abu-Zreig, M.M., \& Abu-Handeh, N.H. Physical durability and stability of olive cake briquettes. Can. Biosyst. Eng. 44, 341-345, (2002). 
47. Kaliyan, N., \&Morey, R.V. Factors affecting the strength and durability of densified products. ASABE Annual International Meeting, Portland, OR, USA (2006).

48. Gresham, G., Emerson, R., Hoover, A., Miller, A., Kenney, K., \& Bauer, W. Evolution and development of effective feedstock specifications. INL/EXT-14-31510 (2013). 